\title{
Construction of Teaching Quality Evaluation System of Higher Vocational Project-Based Curriculum Based on CIPP Model
}

\author{
Hongcheng Jiang and Yiting Liu
}

\begin{abstract}
The project-based classroom teaching has entered the connotative development stage in the development process of Higher Vocational Education in China. It is necessary to evaluate the comprehensive teaching quality including the implementation background, implementation conditions, implementation process and implementation results, but there are few studies on this aspect at present. Therefore, this paper introduces the CIPP evaluation model, based on the analysis of the necessity and applicability of CIPP model in Higher Vocational project-based curriculum teaching quality evaluation, constructs the evaluation index system of Higher Vocational project-based curriculum teaching quality based on CIPP, and discusses the multi-level fuzzy comprehensive evaluation model on the basis of weighting the evaluation index by using AHP. Finally, it takes the teaching quality of cost accounting and practice project in Higher Vocational Colleges as an example to discuss the application of the model.
\end{abstract}

Index Terms-Higher vocational, evaluation, CIPP, project-based curriculum, fuzzy.

\section{INTRODUCTION}

In 1967, the famous American scholar, Stufflebeam, D.L., proposed an improved oriented evaluation model, which is composed of Context Evaluation, Input Evaluation, Process Evaluation and Product Evaluation, which is called CIPP model for short. The background evaluation is mainly used to determine the objectives of the evaluation scheme, and to evaluate the needs, problems, resources and opportunities of the scheme in a specific environment; the input evaluation is based on the background evaluation to judge the feasibility and effectiveness of the information, resources and ways needed to achieve the program objectives; the process evaluation requires continuous supervision and inspection of the whole process of the implementation of the scheme, and make information feedback in time to realize process control; results evaluation is to evaluate the degree of the goal achieved through measurement, judgment, interpretation, confirmation and so on. The four aspects of the CIPP model complement each other. It is advocated that evaluation should not be limited to the evaluation goal is achieved, but should be a process of providing decision-making methods and means for improving the curriculum.

Based on the reference of domestic and foreign literature, Chinese scholars have carried out corresponding research.

Manuscript received November 11, 2020; revised February 8, 2021.

The authors are with Wuxi Institute of Technology, China (e-mail: jhongcheng@126.com, alicekimikris@163.com).
The representative achievements in this field include: Xiao [1] has made a beneficial discussion on the CIPP education evaluation model; Jiang [2] has studied the theory and practice of higher education evaluation based on CIPP; $\mathrm{Wu}$ and Teng [3] have made a beneficial analysis on the development evaluation of Higher Vocational project-based curriculum; Based on the concept of CIPP, Gao [4] discussed the construction of the project-based curriculum teaching evaluation system in Higher Vocational Colleges; Qin Yuan discusses the application of CIPP in the evaluation of Higher Vocational project-based curriculum, but its application process lacks quantitative analysis, and more subjective judgment. Especially, the treatment of fuzzy evaluation index is not enough [5]; in addition, the CIPP model introduced by Zuo [6], Ge [7], Ma [8] has introduced CIPP model to make a beneficial exploration for the practical teaching quality evaluation based on the research of other scholars.

In recent years, the teaching reform of project-based curriculum in Higher Vocational Colleges has developed rapidly, which plays a great role in promoting the curriculum construction and specialty construction. The project-based curriculum has broken the teaching model of the traditional discipline system, and has made great improvements in teaching methods, teaching means, teaching contents and teaching concepts, and has made certain achievements, but, there are few studies on comprehensive teaching quality evaluation including implementation background, implementation conditions, implementation process and implementation results. The traditional teaching quality evaluation method is often based on the goal oriented mode, which is not applicable to the teaching quality evaluation of the project-based curriculum reform in Higher Vocational Colleges. It has become an important aspect of the connotation development of the project-based curriculum reform to explore and improve it. Therefore, this paper studies the construction of teaching quality evaluation system of Higher Vocational project-based curriculum from the perspective of CIPP, in order to further promote the connotation development of Higher Vocational project-based curriculum teaching reform.

\section{APPLiCATION ANALYSIS OF CIPP IN TEACHING QUALITY Evaluation OF Higher VocAtional PROJECT-BASED CURRICULUM}

\section{A. Analysis on the Necessity of CIPP in the Teaching Quality Evaluation of Higher Vocational Project-Based Curriculum}


The traditional teaching quality evaluation method belongs to the Taylor behavior goal oriented model, while CIPP evaluation belongs to the education decision-making oriented model. It is the sublimation of Taylor's goal model, and the curriculum evaluation is more comprehensive and systematic. Compared with the traditional evaluation model, it has obvious advantages in the following five aspects:

\section{1) Teaching evaluation objectives}

The traditional evaluation mode mainly focuses on the evaluation of the realization degree of teaching objectives, which reflects the evaluation of the education goal oriented model; while CIPP curriculum evaluation also pays attention to the evaluation of teaching process, as well as the evaluation of knowledge and ability improvement in the education process, which is the development of the traditional evaluation model, and its main purpose is to improve the teaching quality of courses and provide useful information for decision makers, it reflects the evaluation of educational decision-making oriented model.

\section{2) Teaching evaluation method}

The traditional teaching evaluation pays attention to the evaluation of teaching results, that is, to evaluate the teaching quality results by qualitative and quantitative methods, and even go into the misunderstanding that the evaluation of teaching results is the only standard of teaching quality. However, the content of teaching quality assessed by CIPP is more extensive, which forms the evaluation of four aspects into an organic unity, which not only solves the positioning of the curriculum goal itself. It also evaluates the resources needed to achieve the curriculum objectives, the feasibility and effectiveness of implementation, the whole process of implementation, and the results of implementation, so as to obtain more instructive evaluation information.

\section{3) Feedback mode of teaching evaluation information}

The traditional teaching evaluation is generally given at the end of the course, and gives the evaluation information to provide experience for the next round of teaching, emphasizing post evaluation; while CIPP not only pays attention to post evaluation, but also pays attention to pre-evaluation and in event evaluation, emphasizing timely feedback and communication of information, so as to provide evaluation and control information for achieving higher teaching quality.

\section{4) Teaching evaluation}

The traditional teaching evaluation focuses on the teaching results, but the supervision and guidance on the teaching implementation process is insufficient; however, CIPP teaching evaluation starts from the source of the curriculum teaching, and includes the curriculum setting to the final result into the scope of teaching evaluation, which is conducive to the discovery of various problems in the teaching quality and serves the purpose of the curriculum teaching evaluation.

\section{5) The function of teaching evaluation}

The traditional teaching evaluation function is mainly reflected in the summative function and the diagnostic function. Through the teaching evaluation, the curriculum teaching summary is formed, and the diagnosis service is provided for the existing problems and the next round of the curriculum teaching improvement. However, CIPP model highlights the developmental function of teaching evaluation on the basis of the two functions, and always realizes the teaching objectives throughout the whole process of teaching evaluation. In addition, different teaching evaluation functions or their combinations are flexibly used in different stages of the curriculum teaching, which effectively integrates diagnostic evaluation, formative evaluation and summative evaluation, and achieves the goal of evaluation serving decision-making.

\section{B. The Applicability of CIPP in the Evaluation of Teaching Quality of Higher Vocational Project-Based Curriculum}

Through the analysis of the knowledge and ability demand in the actual work field, the project-based curriculum studies the teaching content by simulating the working situation, sets up typical tasks, provides necessary teaching conditions and teaching resources, guides students to complete the project tasks, and enables students to understand and master professional knowledge and skills through the combination of learning by doing, do in learning and learn in doing, to lay the foundation of knowledge and ability for students to be competent for practical work, to achieve teaching objectives [9]. While, CIPP evaluation method integrates four aspects of evaluation into comprehensive evaluation, and its applicability in the evaluation of Higher Vocational project-based curriculum teaching quality is analyzed as follows:

\section{1) Evaluation on the implementation background of CIPP}

The need of setting up the project-based curriculum comes from the needs of knowledge, skills and quality required by the practical work field for higher vocational graduates to be competent for their jobs. Therefore, the evaluation of the implementation background of the project-based curriculum needs to be connected with the corresponding work fields and needs of the project-based curriculum. The background evaluation of CIPP can effectively evaluate the knowledge, skills and literacy needs of the project-based curriculum, the difficulties that must be overcome when realizing the project-based curriculum objectives, the existing advantages and available resources, as well as the satisfaction of resources and the timing of problem solving through questionnaire survey, symposium, literature review, research and other methods.

\section{2) Evaluation on the implementation conditions of CIPP}

The development of the project-based curriculum requires sufficient research and thinking, the integration of the course content, the setting of typical tasks, the assessment of teaching methods and teaching resources, and the full consideration of the feasibility of implementation and possible teaching effects. The input evaluation of CIPP is based on the background evaluation. Through the methods of interview, investigation, literature review and comparative study, it can effectively evaluate the satisfaction of the project-based curriculum plan, procedures, programs, resources including funds and the possible success of the 
curriculum.

\section{3) Evaluation of the implementation process of CIPP}

In the process of implementation of the project-based curriculum, it is emphasized that students are the center, and the identity of teachers is transformed into a guide, manager and helper. Under the premise of meeting the implementation conditions and Implementation resources, teachers need to take appropriate methods to fully mobilize the enthusiasm of students to participate in the completion of project tasks. The teaching method of integration of teaching and doing also fully reflects the importance of the learning process. CIPP process evaluation is a kind of dynamic evaluation method that keeps up with the goal. It often adopts the methods of attending classes, student questionnaires, symposiums and on-site observation, which can continuously supervise, inspect and feedback information on the implementation process of the project-based curriculum, as well as the teaching organization, teaching methods, teaching means, teaching design, teaching links, scenario design, and projects task arrangement, communication between teachers and students and other performances were evaluated effectively in the implementation process of the project-based curriculum.

\section{4) Evaluation of the implementation results of CIPP}

The results of the implementation of the project-based curriculum reflect the final effect of the implementation of the curriculum and the degree of realization of the goal of the project-based curriculum. It can be evaluated by the knowledge, skills and literacy of students to complete the project tasks, and can also be supplemented by the quality of graduates. CIPP result evaluation mainly adopts the methods of employer evaluation, teacher evaluation, student self-evaluation, social evaluation, etc., which can effectively evaluate the degree of knowledge, skills and literacy that the project-based curriculum has reached to meet the needs of the actual work position, the degree that it should reach, and the gap between them. Therefore, the CIPP model is not only applicable to the teaching quality evaluation of the project-based curriculum in higher vocational education, but also necessary to carry out applied research.

\section{Construction OF MUlti-LEvel FuZzy COMPREHENSIVE EVALUATION MODEL FOR TEACHING QUALITY OF HighER VocATIONAL PROJECT-BASED CURRICULUM BASED ON CIPP}

CIPP involves 2 aspects in the evaluation of teaching quality of Higher Vocational project-based curriculum. The first is about the selection of evaluation content, the selection of key indicators that best reflect the teaching quality of project- based curriculum, and fully reflect the evaluation content of the 4 aspects of CIPP. The second is about the selection of evaluation methods, like which method can better reflect the evaluation indicators and evaluation results.

\section{A. Selection of CIPP Evaluation Content and Indicators}

\section{1) Background evaluation indicators}

the curriculum development background is used to evaluate the value of the project-based curriculum in the actual work field and position, reflecting the closeness of the school and the enterprise when developing the project-based curriculum; the curriculum service object is used to evaluate the main beneficiary groups of the project-based curriculum service, including both the student beneficiary groups and the enterprise beneficiary groups; the curriculum target positioning is used to evaluate the project-based curriculum training objectives, as well as the position in the entire professional training program; the curriculum content development reflects whether the project-based curriculum content can meet the actual needs of knowledge, skills and literacy.

\section{2) Input evaluation index}

the curriculum structure arrangement is used to evaluate the quality of the project-based curriculum content selection, the logical relationship before and after, and the feasibility of teaching; the curriculum standard setting is used to evaluate the professional standard and learning standard of the project-based curriculum; the curriculum teaching document is used to evaluate the teaching scheme to guarantee the implementation of the project-based curriculum, including outline, teaching plan, lesson plan, lesson preparation notes, and other relevant teaching materials; the available curriculum resources are used to evaluate the resources that can be used in the development of the project-based curriculum, or the support that can be obtained from various enterprises and institutions and the proofreading Institute, so as to reflect the degree of guarantee that the curriculum objectives can be achieved.

\section{3) Process evaluation index}

the implementation degree of teaching scheme is used to evaluate the degree of teaching scheme being fully implemented in the implementation of teaching process; the curriculum teaching content is used to evaluate the degree of the project-based curriculum content being implemented in the implementation of teaching process, and the degree of the connection between theory and practice in the project-based curriculum content; course teaching method is used to evaluate the degree of the use of teaching means, language expression, blackboard writing design, teacher and student communication, and other aspects in the project-based curriculum implementation; the satisfaction degree of teaching conditions is used to measure the degree of meeting the required resources in the implementation of teaching; the learning performance of students is used to evaluate the students' thinking ability, team cooperation, interpersonal communication and other learning performances in project task learning.

\section{4) Results evaluation indicators}

attendance and discipline were used to evaluate the enthusiasm of students to participate in the completion of project tasks and the popularity of the course; project completion was used to evaluate the knowledge and skills of students to master project design, reflecting the quantity and quality of project tasks completed; theoretical knowledge test results were used to reflect the students' mastery of basic theoretical knowledge and its basic application, generally, it 
is expressed by quantitative values; the professional ability and quality are used to evaluate the training of the professional ability and professional quality required by the course for students to engage in actual work; the evaluation of the course by students is used to feedback strengths and weaknesses of students in various aspects of the course.

\section{B. Selection of Evaluation Methods}

In the process of implementing the background evaluation, input evaluation, process evaluation and result evaluation of the project-based curriculum, in addition to more qualitative evaluation content and quantitative evaluation index information, CIPP is often affected by some uncertain factors and the fuzziness of qualitative indicators. In addition, CIPP also goes beyond the realization of the evaluation the project-based curriculum objectives and pays more attention to the evaluation information, which is used for the project-based curriculum decision-making and improvement. Therefore, appropriate methods should be adopted in the teaching quality evaluation of CIPP project, which can not only effectively integrate the qualitative and quantitative indicator information, but also overcome the defects of information uncertainty and ambiguity. The best way to meet these requirements is the method of the evaluation of the fuzziness mathematics. This method is based on the membership degree theory of the fuzziness mathematics, with strong systematicness and clear evaluation results, and can also make a better evaluation of the qualitative information with strong fuzziness and difficulty in quantifying.

\section{The Construction of CIPP}

The following steps can be adopted for the construction of the CIPP's mathematical evaluation model ${ }^{[10]}$ :

\section{1) Establish index set}

According to the CIPP evaluation model, the key indicators of background evaluation, input evaluation, process evaluation and result evaluation are selected purposefully, and classified according to levels to form an indicator set, including level 1 indicators, level 2 indicators and level 3 indicators. If $U=\left\{U_{1}, U_{2}, \ldots U_{n}\right\}$ represents the first level indicator set, $U_{i}$ represents the i-level index for evaluating the teaching quality of the project-based curriculum; similarly, the first level index $\mathrm{U}_{\mathrm{i}}$ can be expanded to form a secondary index set $\mathrm{U}_{\mathrm{i}}=\left\{\mathrm{U}_{\mathrm{i} 1}, \mathrm{U}_{\mathrm{i} 2}, \ldots \mathrm{U}_{\mathrm{im}}\right\}$, where $U_{i j} \in U_{i}, i=1,2,3 \ldots, n ; j=1,2,3 \ldots, m$; The second level index $U_{i j}$ is expanded to form the third level index set $\mathrm{U}_{\mathrm{ij}}=\left\{\mathrm{U}_{\mathrm{ij} 1}, \mathrm{U}_{\mathrm{ij} 2}, \ldots \mathrm{U}_{\mathrm{ijt}}\right\}, \quad$ where $\quad \mathrm{U}_{\mathrm{ijL}} \in \mathrm{U}_{\mathrm{ij}}, \quad \mathrm{i}=1,2,3 \ldots, \mathrm{n}$; $\mathrm{j}=1,2,3 \ldots, \mathrm{m} ; \mathrm{L}=1,2,3, \ldots \mathrm{t}$. Therefore, in the case of multi-level classification, any level index set must meet the following conditions:

1) Any index of any level is an element of indicator set $U$;

2) $U_{1} \cup U_{2} \cup \ldots \cup U_{n}=U$;

3) For any $i \neq h, U_{i} \cap U_{h} \neq \varnothing$,

\section{2) Set up a collection of comments}

The set $\mathrm{V}$ is used to represent the comment set, $\mathrm{V}=\left\{\mathrm{V}_{1}, \mathrm{~V}_{2}, \ldots \mathrm{V}_{\mathrm{k}}\right\}$ indicates that $\mathrm{V}_{\mathrm{k}}$ refers to the Kth level of teaching quality evaluation of the project-based curriculum.

\section{3) Establish the weight set of analysis index}

The analytic hierarchy process (AHP) can be used to allocate the weight of the index set, so that the weight allocation of each index in $U_{i}$ is $A_{i}=\left(A_{i 1}, A_{i 2}, \ldots A_{i m}\right)$ 。Where $\sum_{i=1}^{n} a_{i m}=1, a_{i} \geq 0, \mathrm{i}=1,2, \ldots \mathrm{n}$.

\section{4) Carry on the fuzzy comprehensive evaluation}

1) If $R_{i}$ is a single factor evaluation matrix, the evaluation vector of corresponding level is obtained: $B_{j}=A_{i}$. $\mathrm{R}_{\mathrm{i}}=\left(\mathrm{b}_{\mathrm{i} 1}, \mathrm{~b}_{\mathrm{i} 2}, \ldots \mathrm{b}_{\mathrm{im}}\right), \mathrm{i}=1,2, \ldots, \mathrm{s}$.

2) If each $U_{i}$ is taken as a factor, $K=\left(u_{1}, u_{2}, \ldots u_{s}\right)$, then the single factor evaluation matrix of $\mathrm{K}$ is as follows:

$$
\mathrm{R}=\left[\begin{array}{c}
B_{1} \\
B_{2} \\
\ldots \\
B_{s}
\end{array}\right]=\left[\begin{array}{cccc}
b_{11} & b_{12} & \ldots & b_{1 m} \\
b_{21} & b_{22} & \ldots & b_{2 m} \\
\ldots & \ldots & \ldots & \ldots \\
b_{s 1} & b_{s 2} & \ldots & b_{s m}
\end{array}\right]
$$

Thus, the fuzzy evaluation vector is obtained:

$$
\begin{gathered}
B=A \\
R=\left(b_{1}, b_{2}, \ldots b_{n}\right)
\end{gathered}
$$

Finally, the evaluation score can be obtained by multiplying the evaluation vector and the vector assigned by the grade of the evaluation set, and the evaluation level of the project-based curriculum can be obtained by comparing the evaluation vector with the evaluation set.

\section{Discussion ON MODEl APPliCATION}

Taking the teaching quality evaluation of the project-based curriculum cost accounting and practice as an example in accounting major in our school, this paper discusses the application of the model. This course takes the cost accounting of the mechanical and electrical manufacturing industry as the background, and takes the training of students to master the cost accounting methods and skills of the mechanical and electrical manufacturing industry as the main line. By setting up simulation teaching scenarios and project tasks, it guides students to do in learning and learn in doing, and trains students to master the basic knowledge, skills and literacy of cost accounting. At present, the teaching quality of this project type course is evaluated by the method of CIPP based on the fuzziness evaluation, and the process is as follows:

\section{A. Establishment of a Set of Comprehensive Evaluation Indicators Based on CIPP}

The teaching quality of the cost accounting and practice project is set as the first level evaluation index, which belongs to the comprehensive index; the second level evaluation index is the background evaluation, input evaluation, process evaluation and result evaluation of CIPP; according to the evaluation content of the four aspects of the second level index, the key indicators are selected from the cost accounting and practice project curriculum, so as to form 
the evaluation index set; Thus, the index system of the CIPP

shown in Table I:

based on the comprehensive evaluation can be obtained, as

TABLE I: THE INDEX SYSTEM OF TEACHING QUALITY OF THE PROJECT-BASED CURRICULUM BASED ON CIPP

\begin{tabular}{|c|c|c|c|c|c|c|}
\hline \multirow{2}{*}{ First level indicators } & \multirow{2}{*}{ Second level indicators } & \multirow{2}{*}{ Third level indicators } & \multicolumn{4}{|c|}{ Comments collection } \\
\hline & & & $\mathrm{V}_{1}$ & $\mathrm{~V}_{2}$ & $\mathrm{~V}_{3}$ & $\mathrm{~V}_{4}$ \\
\hline \multirow{18}{*}{$\begin{array}{c}\text { The project-based curriculum } \\
\text { teaching quality } U\end{array}$} & \multirow{4}{*}{ Background assessment $U_{1}$} & Background of curriculum development $U_{11}$ & 0.7 & 0.2 & 0.1 & 0 \\
\hline & & curriculum service target $\mathrm{U}_{12}$ & 0.9 & 0.1 & 0 & 0 \\
\hline & & Positioning of curriculum objectives $U_{13}$ & 0.8 & 0.1 & 0.1 & 0 \\
\hline & & curriculum content development $\mathrm{U}_{14}$ & 0.7 & 0.1 & 0.1 & 0.1 \\
\hline & \multirow{4}{*}{ Input evaluation $\mathrm{U}_{2}$} & curriculum structure arrangement $\mathrm{U}_{21}$ & 0.8 & 0.1 & 0.1 & 0 \\
\hline & & Curriculum standard setting $\mathrm{U}_{22}$ & 0.7 & 0.1 & 0.1 & 0.1 \\
\hline & & Curriculum teaching documents $\mathrm{U}_{23}$ & 0.9 & 0.1 & 0 & 0 \\
\hline & & Curriculum resources available $U_{24}$ & 0.6 & 0.2 & 0.1 & 0.1 \\
\hline & \multirow{5}{*}{ Process evaluation $\mathrm{U}_{3}$} & Implementation level of teaching plan $U_{31}$ & 0.8 & 0.1 & 0.1 & 0 \\
\hline & & Curriculum teaching content $\mathrm{U}_{32}$ & 0.9 & 0.1 & 0 & 0 \\
\hline & & Curriculum teaching methods $\mathrm{U}_{33}$ & 0.8 & 0.1 & 0.1 & 0 \\
\hline & & Satisfaction of teaching conditions $\mathrm{U}_{34}$ & 0.7 & 0.1 & 0.1 & 0.1 \\
\hline & & Student learning performance $\mathrm{U}_{35}$ & 0.7 & 0.1 & 0.1 & 0.1 \\
\hline & \multirow{5}{*}{ Result evaluation $\mathrm{U}_{4}$} & Attendance and discipline $\mathrm{U}_{41}$ & 0.7 & 0.2 & 0.1 & 0 \\
\hline & & Project completion $\mathrm{U}_{42}$ & 0.8 & 0.1 & 0.1 & 0 \\
\hline & & Test results of theoretical knowledge $U_{43}$ & 0.7 & 0.1 & 0.1 & 0.1 \\
\hline & & Professional ability and quality $\mathrm{U}_{44}$ & 0.8 & 0.1 & 0.1 & 0 \\
\hline & & Students' evaluation curriculums $\mathrm{U}_{45}$ & 0.8 & 0.1 & 0.1 & 0 \\
\hline
\end{tabular}

\section{B. Establishment of Comment Collection}

The evaluation grade of the teaching quality of the project-based curriculum is represented by the evaluation set $\mathrm{V}=\left\{\mathrm{V}_{1}, \mathrm{~V}_{2}, \mathrm{~V}_{3}, \mathrm{~V}_{4}\right\}$, among which: $\mathrm{V}_{1}$ - excellent, with a score of $\geq 90 ; V_{2^{-}}$good, with a score of $\geq 80$, but $<90 ; V_{3^{-}}$general, with a score of $\geq 70$, but $<80 ; V_{4}$-improve, the score $<70$.

\section{Establish Analysis Index Weight Set}

\section{1) Using AHP weight determination method}

Analytic hierarchy process (AHP) is used to allocate the weight of each index. Taking the teaching quality evaluation (Level one Index) as the target level, the CIPP (Level two index) as the standard level $\left(\mathrm{U}_{1} \sim \mathrm{U}_{4}\right)$, and the specific indicators (Level three index) constitute the scheme level, the AHP multi-level model is established, and the relative importance of each evaluation index is determined and assigned according to the 1 9 scale method based on scores of teaching quality evaluation experts.

\section{2) Construction of judgment matrix}

Based on the valuation of the criteria layer, the criteria layer judgment matrix $r_{U}$ is constructed as follows:

$$
r_{U}=\left[\begin{array}{cccc}
1 & 1 / 2 & 1 / 3 & 1 \\
2 & 1 & 1 / 2 & 2 \\
3 & 2 & 1 & 3 \\
1 & 1 / 2 & 1 / 3 & 1
\end{array}\right]
$$

There into, $U_{i j}>0, U_{i j}=1(i=j), U_{j i}=1 / U_{i j o}$

Similarly, the scheme level judgment matrix can be constructed based on the scheme level valuation, $r_{U 1}$ is set as the background evaluation scheme level judgment matrix, and $r_{U 2}, r_{U 3}$ and $r_{U 4}$ are the input evaluation, process evaluation and result evaluation scheme level judgment matrix, respectively, from which the judgment matrix of each scheme level can be obtained:

$$
\begin{aligned}
& r_{U 1}=\left[\begin{array}{cccc}
1 & 2 & 1 / 2 & 1 / 2 \\
1 / 2 & 1 & 1 / 4 & 1 / 4 \\
2 & 4 & 1 & 1 \\
2 & 4 & 1 & 1
\end{array}\right] \\
& r_{U 2}=\left[\begin{array}{cccc}
1 & 1 / 2 & 1 & 1 / 3 \\
2 & 1 & 1 & 1 / 2 \\
1 & 1 & 1 & 1 / 3 \\
3 & 2 & 3 & 1
\end{array}\right] \\
& r_{U 3}=\left[\begin{array}{ccccc}
1 & 1 & 1 / 2 & 1 & 1 / 3 \\
1 & 1 & 1 / 2 & 1 & 1 / 3 \\
2 & 2 & 1 & 2 & 1 / 2 \\
1 & 1 & 1 / 2 & 1 & 1 / 3 \\
3 & 3 & 2 & 3 & 1
\end{array}\right]
\end{aligned}
$$




$$
r_{U 4}=\left[\begin{array}{ccccc}
1 & 1 / 3 & 1 / 2 & 1 / 4 & 1 / 2 \\
3 & 1 & 2 & 1 / 2 & 2 \\
2 & 1 / 2 & 1 & 1 / 2 & 1 \\
4 & 2 & 2 & 1 & 2 \\
2 & 1 / 2 & 1 & 1 / 2 & 1
\end{array}\right]
$$

There into, $U_{i j k}>0, U_{i j k}=1(i=k), U_{k j i}=1 / U_{i j k}$.

\section{3) Using AHP software to calculate index weight}

The consistency ratio threshold, the maximum consistency ratio and the maximum proportion of missing items of AHP software are set to be 5\%. The weight of each indicator is obtained based on the sequence consistency and basic consistency test by using AHP software. If $W_{U}$ represents the weight vector of the standard layer, and $W_{U 1}, W_{U 2}, W_{U 3}$ and $W_{U 4}$ represent the weight vector of each scheme layer, the weight vectors calculated by AHP software are as follows:

$W_{U}=\left(U_{1}, U_{2}, U_{3}, U_{4}\right)=(0.1411,0.2628,0.4550,0.1411)$

$W_{U 1}=\left(U_{11}, U_{12}, U_{13}, U_{14}\right)=(0.1819,0.0909,0.3636,0.3636)$

$W_{U 2}=\left(U_{21}, U_{22}, U_{23}, U_{24}\right)=(0.1433,0.2243,0.1704,0.4620)$

$W_{U 3}=\left(U_{31}, U_{32}, U_{33}, U_{34}, U_{35}\right)=(0.124,0.124,0.234,0.124$, $0.394)$

$W_{U 4}=\left(U_{41}, U_{42}, U_{43}, U_{44}, U_{45}\right)=(0.0818,0.2541,0.1545$, $0.3551,0.1545$ )

\section{Fuzzy Comprehensive Evaluation}

The project-based curriculum evaluation group invited 10 members, including enterprise experts, school teaching administrative director, department head, senior professional title teachers, teachers and other members to score, according to the indicators of the project-based curriculum of cost accounting and practice, and summarize the scoring results in the evaluation set in Table I (calculated according to the proportion of superior membership). Thus, the fuzzy evaluation of indicators at all levels can be carried out. The process is as follows:

\section{1) Fuzzy evaluation of secondary index}

The evaluation matrix of "background evaluation" can be obtained from Table I

$$
R_{U 1}=\left[\begin{array}{cccc}
0.7 & 0.2 & 0.1 & 0 \\
0.9 & 0.1 & 0 & 0 \\
0.8 & 0.1 & 0.1 & 0 \\
0.7 & 0.1 & 0.1 & 0.1
\end{array}\right]
$$

Then

$$
\begin{aligned}
B_{U 1}=W_{U 1} \times R_{U 1}= & {\left[\begin{array}{llll}
0.1819 & 0.0909 & 0.3636 & 0.3636
\end{array}\right] \times } \\
& {\left[\begin{array}{cccc}
0.7 & 0.2 & 0.1 & 0 \\
0.9 & 0.1 & 0 & 0 \\
0.8 & 0.1 & 0.1 & 0 \\
0.7 & 0.1 & 0.1 & 0.1
\end{array}\right] } \\
& =\left[\begin{array}{llll}
0.7545 & 0.1182 & 0.0909 & 0.0364
\end{array}\right]
\end{aligned}
$$

Taking the median score of the comment set as the calculation basis, the score vector of the comment set is: $\mathrm{V}=\left[\begin{array}{llll}95 & 85 & 75 & 60\end{array}\right]$. The score of "background evaluation" $M_{u 1}$ can be obtained as follows:

$$
M_{l 1}=B_{U 1} \times V=\left[\begin{array}{llll}
0.7545 & 0.1182 & 0.0909 & 0.0364
\end{array}\right] \times
$$

$\left[\begin{array}{llll}95 & 85 & 75 & 60\end{array}\right]^{T}=90.7273$

Similarly, the evaluation vectors and scores of the other three criteria layers can be obtained:

$$
\begin{aligned}
& \text { "Input } \begin{array}{cccc}
\text { evaluation" } & \text { judgment } & \text { vector } \\
B_{U 2}=W_{U 2} \times R_{U 2}=\left[\begin{array}{llll}
0.7022 & 0.1462 & 0.0830 & 0.0686
\end{array}\right] & \\
\text { "Input evaluation" score } \mathrm{M}_{\mathrm{U} 2}=\mathrm{B}_{\mathrm{U} 2} \times \mathrm{V}=89.4767 & \\
\text { "process } & \text { evaluation" } & \text { judgment } & \text { vector } \\
B_{U 3}=W_{U 3} \times R_{U 3}=\left[\begin{array}{llll}
0.7606 & 0.1 & 0.0876 & 0.0518
\end{array}\right] \\
\text { "process evaluation" score } \mathrm{M}_{\mathrm{U} 3}=\mathrm{B}_{\mathrm{U} 3} \times \mathrm{V}=89.4767=90.435 \\
\text { "result } \quad \text { evaluation" } & \text { judgment } & \text { vector } \\
B_{U 4}=W_{U 4} \times R_{U 4}=\left[\begin{array}{llll}
0.7764 & 0.1082 & 0.1 & 0.0155
\end{array}\right] & \\
\text { "result evaluation" score } \mathrm{M}_{\mathrm{U} 4}=\mathrm{B}_{\mathrm{U} 4} \times \mathrm{V}=89.4767=91.3775 \\
\text { 2) Fuzzy evaluation of first index }
\end{array}
\end{aligned}
$$

According to the above fuzzy evaluation of secondary index, each judgment vector of the criterion layer is combined into the fuzzy evaluation of first index $R_{u}$, as follows:

$$
R_{u}=\left[\begin{array}{cccc}
0.7545 & 0.1182 & 0.0909 & 0.0364 \\
0.7022 & 0.1462 & 0.0830 & 0.0686 \\
0.7606 & 0.1 & 0.0876 & 0.0518 \\
0.7764 & 0.1082 & 0.1 & 0.0155
\end{array}\right]
$$

By multiplying the weight vector $W_{u}$ and $R_{u}$ of the target layer, the evaluation vector of the target layer can be obtained as follows:

$$
B=W_{U} \times R_{u}=\left[\begin{array}{llll}
0.7466 & 0.1159 & 0.0886 & 0.0489
\end{array}\right]
$$

Therefore, the total score of fuzzy comprehensive evaluation of the target layer is as follows: $M=B \times V=90.3574$

\section{SUMMARY OF COMMENTS}

According to the score level of the evaluation set, the total score of the teaching quality of the project-based curriculum cost accounting and practice is over 90 , and the grade is excellent. However, the background evaluation, process evaluation and result evaluation of the project-based curriculum are all excellent, only the input evaluation score is 89.4767 , slightly lower than 90 points, which belongs to good, indicating that there is a relatively weak point in the input evaluation index, which will provide suggestions for future teaching improvement.

In short, this paper discusses the construction of the project-based curriculum teaching quality fuzzy evaluation system from the perspective of CCIP, which is helpful to the connotation development of Higher Vocational project-based curriculum reform, and plays a positive role in promoting the research of teaching quality evaluation of Higher Vocational project-based curriculum.

\section{CONFLICT OF INTEREST}

The authors declare no conflict of interest. 


\section{AUTHOR CONTRIBUTIONS}

Hongcheng Jiang wrote this paper, revision, finalization, submission and contact, accounting for $70 \%$ of the contribution; Yiting Liu participated in the literature search, model construction analysis and discussion, and was responsible for proofreading and translation of this paper, accounting for $30 \%$ of the contribution.

\section{ACKNOWLEDGMENT}

Thanks to Wuxi Institute of Technology for providing a good teaching and research platform, laying a good foundation for the two authors of this paper to concentrate on teaching and research; Also, we would like to thank to our colleagues and family members for their silent support, which is the driving force for two authors to study hard all the time.

\section{REFERENCES}

[1] Y. J. Xiao, "Analysis of CIPP education evaluation model," Education Science, vol. 3, pp. 42-45, Jun 2003.

[2] G. Y. Jiang, "Theory and practice of higher education evaluation based on CIPP," China Higher Education Research, vol. 8, pp. 10-12, Aug 2007.

[3] Q. Wu and G. Teng, "Developmental evaluation analysis of the Project-based Curriculum in higher vocational education," Vocational and Technical Education, vol. 29, pp. 18-20, Oct 2011.

[4] J. J. Gao, "Exploration on the construction of the project-based curriculum teaching evaluation system in higher vocational education," China Vocational and Technical Education, vol. 5, pp. 53-54, Feb 2010.

[5] Q. Yuan, "Application of CIPP evaluation model in the project-based curriculum evaluation of higher vocational education," China Vocational and Technical Education, vol. 35, pp. 53-57, Dec 2013.

[6] F. L. Zuo, "Research on the construction of post practice quality management system based on CIPP evaluation," Vocational Education Forum, vol. 27, pp. 85-88, Sep 2013.
[7] G. F. Ge, "Evaluation of comprehensive practical teaching in higher vocational colleges Based on CIPP model," Education and Occupation, vol. 23, pp. 157-159, Aug 2014.

[8] L. L. Ma, "Construction of evaluation index system of comprehensive practical activity curriculums based on CIPP model," Teaching and Management, vol. 3, pp. 115-118, Mar 2020.

[9] Y. Meng, "On the evaluation system of practical teaching in media colleges based on CIPP model," Media, vol. 9, pp. 79-81, Sep 2020.

[10] D. Du, Q. H. Pang, and Y. Wu, Modern Comprehensive Evaluation Method and Case Selection, 2rd ed. Beijing: Tsinghua University press, 2012, pp. 34-61

Copyright $\odot 2021$ by the authors. This is an open access article distributed under the Creative Commons Attribution License which permits unrestricted use, distribution, and reproduction in any medium, provided the original work is properly cited (CC BY 4.0).

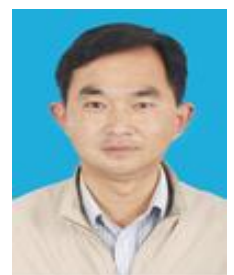

Hongcheng Jiang was born in Fengcheng city, Jiangxi province, in 1975. He is an associate professor of Finance and Economics School of Wuxi Institute of Technology. The research direction is small and micro enterprise management, higher vocational accounting education.

Some latest publication: 1). Influencing factors and optimization countermeasures of financing environment for small and micro businesses in southern Jiangsu. Modern Business Trade Industry[J].2018(21). 2). Analysis of the causes of College Students' over consumption and Countermeasures. Modern Business Trade Industry[J].2020(30). 3). Investigation and thinking of College Students over consumption under the background of Internet Finance. Modern Business Trade Industry[J].2020(30).

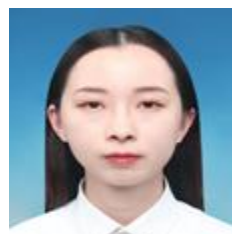

Yiting Liu was born in Wuxi, Jiangsu province, in 1994. She is an assistant of Finance and Economics School of Wuxi Institute of Technology. The research direction is accounting basis and practice, the management of small and medium sized enterprises. Some latest publication: Analysis of strategic issues of Adnams by Ansoff's Matrix. 